\title{
Raman Spectroscopic Study of the Valinomycin-KSCN Complex
}

\author{
Irvin M. Asher, Kenneth J. Rothschuld and H. Eugene Stanley \\ Harvard-MIT Program in Health Sciences and Technology \\ Massachusetts Institute of Technology \\ Cambridge, Mass. 02139, U.S.A.
}

(Received 25 February 1974, and in revised form 30 May 1974)

\begin{abstract}
This paper reports the first Raman spectroscopic study of the potassium complex of the cation-specific antibiotic valinomycin. Complete Raman spectra (140 to $3600 \mathrm{~cm}^{-1}$ ) of crystalline valinomycin-KSCN and its $\mathrm{CCl}_{4}, \mathrm{CHCl}_{3}$ and $\mathrm{C}_{2} \mathrm{H}_{5} \mathrm{OH}$ solutions are presented and used to probe the structure of the complex in these environments. In all cases a single, narrow peak is observed in the ester $\mathrm{C}=\mathrm{O}$ stretch region (1750 to $1775 \mathrm{~cm}^{-1}$ ) which contrasts strongly with the broad bands observed in solutions of uncomplexed valinomycin. This is consistent with the presence of a single conformation in which all six ester $\mathrm{C}=\mathrm{O}$ groups co-ordinate an enclosed potassium ion. We find that although the ester $\mathrm{C}=\mathrm{O}$ stretch frequencies of the complex are similar in the solid state and in non-polar solution $\left(\sim 1770 \mathrm{~cm}^{-1}\right)$ they are considerably different in the presence of polar solvents $\left(\sim 1756 \mathrm{~cm}^{-1}\right)$; this may indicate that the complexed potassium ion is still free to interact with nearby solvent ions (and possibly its counterion) through gaps in the hydrophobic "shield" provided by the hydrocarbon residues of valinomycin. In contrast the amide $\mathrm{C}=\mathrm{O}$ frequencies of the complex $\left(\sim 1650 \mathrm{~cm}^{-1}\right)$ are solvent-independent. These groups are apparently strongly hydrogen-bonded to provide a rather rigid, compact framework for the complex conformation.
\end{abstract}

\section{Introduction}

The macrocyclic depsipeptide valinomycin $\left(\mathrm{C}_{54} \mathrm{~N}_{6} \mathrm{O}_{18} \mathrm{H}_{90}\right)$ is a membrane-active antibiotic with remarkably selective ion-binding properties. Its ability to facilitate potassium ion transport across mitochondrial membranes (Pressman, 1965) and egg lecithin bilayers (Shemyakin et al., 1969) suggests that a study of its complexation mechanisms may help elucidate selective ionic transport in other systems.

The valinomycin molecule consists of the sequence (L-valine, $D$ - $\alpha$-hydroxyisovaleric acid, D-valine, L-lactic acid) repeated three times (Shemyakin et al., 1963). The structure of uncomplexed valinomycin crystals (monoclinic, space group $P 2_{1}$ ) grown from warm $n$-octane has been determined by X-ray diffraction (Duax et al., 1972). Unique to this conformation is the presence of intramolecularly hydrogen-bonded ester $\mathrm{C}=\mathrm{O}$ groups (Fig. 1). Although recent Raman spectroscopic data indicate that this structure is maintained in valinomycin recrystallized from several other solvents $\left(\mathrm{CCl}_{4}, \mathrm{CHCl}_{3}, \mathrm{CH}_{3}\left(\mathrm{CH}_{2}\right)_{2} \mathrm{Cl}, \mathrm{CH}_{3} \mathrm{CN}\right)$, a different solid-state conformation is found to exist in valinomycin freshly recrystallized from $p$-dioxane or o-dichlorobenzene (Rothschild et al., 1973; Asher, Rothschild, Anastassakis \& Stanley, manuscript in preparation). 


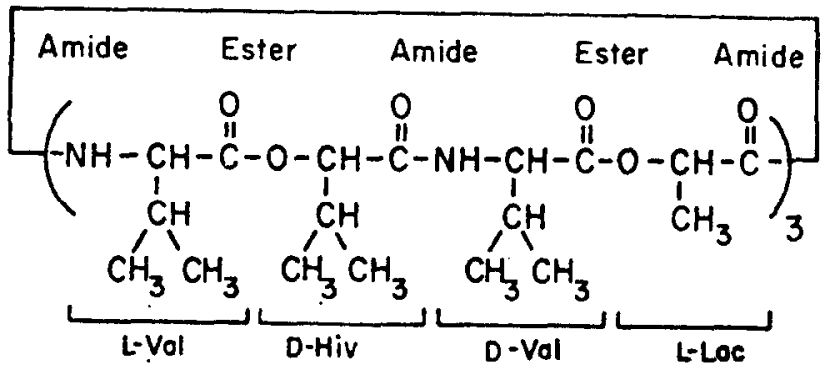

(a)

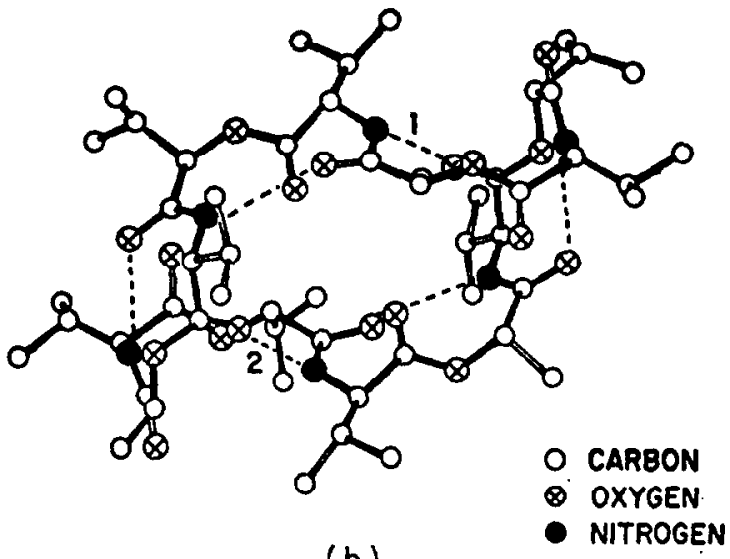

(b)

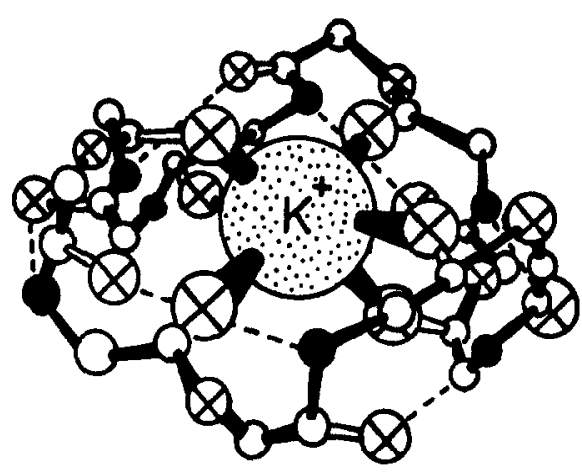

(c)

Fıg. 1. (a) Primary sequence of valinomycin showing alternating amide and ester linkages. Hiv, $\alpha$-hydroxyisovaleric acid; Lac, lactic acid.

(b) Structure of uncomplexed valinomycin crystallized from $n$-octane; from Duax et al. (1972). 1 and 2 indicate ester $\mathrm{C}=\mathrm{O} \ldots \mathrm{HN}$ hydrogen bonding.

(c) Structure of the valinomycin-K $\mathrm{K}^{+}$complex; from Pinkerton et al. (1969), in which hydrocarbon sidegroups have been omitted. All six amide $\mathrm{C}=\mathrm{O}$ groups are H-bonded, and all six ester $\mathrm{C}=\mathrm{O}$ groups co-ordinate the enclosed cation.

A variety of different valinomycin conformations exists in solution; their structure and relative concentrations at equilibrium depend on the polarity and hydrogenbonding ability of the solvent. Nuclear magnetic resonance (Haynes et al., 1969; Shemyakin et al., 1969; Patel, 1973; Patel \& Tonelli, 1973; Grell \& Funck, 1973), infrared absorption spectroscopy (Shemyakin et al., 1969; Grell \& Funck, 1973) and more recently, laser Raman spectroscopy (Rothschild, Asher, Anastassakis \& Stanley, manuscript in preparation) have been used to investigate the details of these conformations. In the last case this mixture of conformations is responsible for the appearance of broad bands in the amide $\left(=1650 \mathrm{~cm}^{-1}\right)$ and ester $\left(=1750 \mathrm{~cm}^{-1}\right)$ $\mathrm{C}=\mathbf{0}$ stretch region.

The structure of the valinomycin-potassium ion complex was determined by Pinkerton et al. (1969) using X-ray crystallographic methods. The crystals were grown from a 1:1 mixture of chloroform and $m$-xylene which was shaken with an aqueous solution of potassium aurichloride $\left(\mathrm{KAuCl}_{4}\right)$. Such crystals are yellow, triclinic (space group $P_{1}$ ) with one molecule of complex per unit cell. Complex 
formation depended critically on the counterion used. The potassium ion was found to be held in the internal cavity of the valinomycin molecule by co-ordination to all six ester $\mathrm{C}=\mathrm{O}$ groups (Fig. $1(\mathrm{c})$ ); the $\mathrm{K}^{+}---\mathrm{O}$ distance was found to be $\sim 2.7 \AA$. The valinomycin backbone forms three complete sine waves as it circles around the enclosed ion; this framework is held comparatively rigid by intramolecular $\mathrm{H}$-bonds formed by all six amide $\mathrm{C}=0$ groups $(\mathrm{H} . . \mathrm{O}$ distances $\sim 1.9 \AA$ ). The $\mathrm{X}$-ray structure of the crystalline complex suggests that valinomycin carries potassium ions across the hydrophobic region of membranes by surrounding them in a "cage" whose outer surface (containing 12 aliphatic residues) is considerably less hydrophilic than the bare ion.

This conformation of the complex has been inferred to exist in chloroform and methanol solutions by nuclear magnetic resonance (Haynes et al., 1969; Shemyakin et al., 1969; Ohnishi \& Urry, 1970; Patel, 1973; Patel \& Tonelli, 1973) and infrared absorption (Shemyakin et al., 1969; Grell \& Funck, 1973) techniques. For example. the infrared spectrum of valinomycin in chloroform displays amide and ester $\mathrm{C}=\mathrm{O}$ stretch frequencies at $1661 \mathrm{~cm}^{-1}$ and $1755 \mathrm{~cm}^{-1}$, respectively; these shift to 1657 $\mathrm{cm}^{-1}$ and $1739 \mathrm{~cm}^{-1}$, on adding $n-\mathrm{C}_{11} \mathrm{H}_{23} \mathrm{OSO}_{3} \mathrm{~K}$ (Shemyakin et al., 1969). This downward shift and the concomitant narrowing of the ester $\mathrm{C}=0$ peak is taken as evidence for the uniform bonding of all six ester $\mathrm{C}=\mathrm{O}$ groups to an enclosed potassium ion.

This paper reports the first Raman spectroscopic study of the valinomycinpotassium complex. Unlike the references previously cited, it includes observations of the complex in the solid state and in non-polar $\left(\mathrm{CCl}_{4}\right)$ solution. The former provides a more direct comparison with the $\mathrm{X}$-ray crystallographic structure of Pinkerton et al. (1969); the latter allows one to observe the effects of solvent polarity on the conformation of the complex.

\section{Materials and Methods}

Uncomplexed valinomycin was obtained commercially from Calbiochem (San Diego, Calif.) and used without further purification. Valinomycin-potassium complex was prepared by adding excesses of uncomplexed valinomycin and $\mathrm{KSCN}$ (or $\mathrm{KCl}$ ) to ethanol and extracting the supernatant. Additional powdered valinomycin-KSCN complex was obtained from Professor V. T. Ivanov and his colleagues at the Shemyakin Institute for the Chemistry of Natural Products, Moscow, prepared as in Ivanov et al. (1973). No spectral differences were observed between samples prepared by these two methods.

Raman spectra were taken of the powdered complex and its solutions in $\mathrm{CCl}_{4}, \mathrm{CHCl}_{3}$, and $\mathrm{C}_{2} \mathrm{H}_{5} \mathrm{OH}$ using a SPEX Ramalog 4 system in conjunction with a $4 \mathrm{~W}$ argon ion laser (Spectra-Physics Model 124). This system will be described in detail elsewhere (Asher, Rothschild, Anastassakis \& Stanley, manuscript in preparation). All samples were held in 1-mm inner diameter glass capillary tubes mounted perpendicular to the scattering plane. The effects of sample fluorescence were minimized by using the violet $4579 \AA$ argon line and moderately slow scanning speeds (3 to $\left.12 \mathrm{~cm}^{-1} / \mathrm{min}\right)$. Spectral resolutions of 3 to $5 \mathrm{~cm}^{-1}$ were sufficient for our purposes. Optical rotatory dispersion spectra of the valinomycin-KSCN complex in ethanol solution were taken with a Carey model 60 spoctro polarimeter.

\section{Results}

Our results are displayed in Figures 2 and 4 and Tables 1 and 2 (the mode assignments are based on Asher et al., manuscript in preparation). In section (a) to (c) below we will confine our attention to the 1600 to $1800 \mathrm{~cm}^{-1}$ region, although complex forma- 
tion-induced changes are observed throughout the valinomycin spectrum (section (d)). The stretch vibrations of the amide $\left(\sim 1650 \mathrm{~cm}^{-1}\right)$ and ester $\left(\sim 1750 \mathrm{~cm}^{-1}\right) \mathrm{C}=0$ groups have been shown to be particularly sensitive to valinomycin conformation in previous Raman spectroscopic studies (Rothschild et al., 1973).

The Raman spectrum of uncomplexed valinomycin powder recrystallized from $n$-octane (Fig. 2(a)), $\mathrm{CCl}_{4}$ or $\mathrm{CHCl}_{3}$ contains four distinct peaks in the 1600 to 1800 $\mathrm{cm}^{-1}$ region, indicating the presence of both "free" and intramolecularly hydrogenbonded amide $\mathrm{C}=0$ groups (1675 $\mathrm{cm}^{-1}$ and $1649 \mathrm{~cm}^{-1}$, respectively) and both

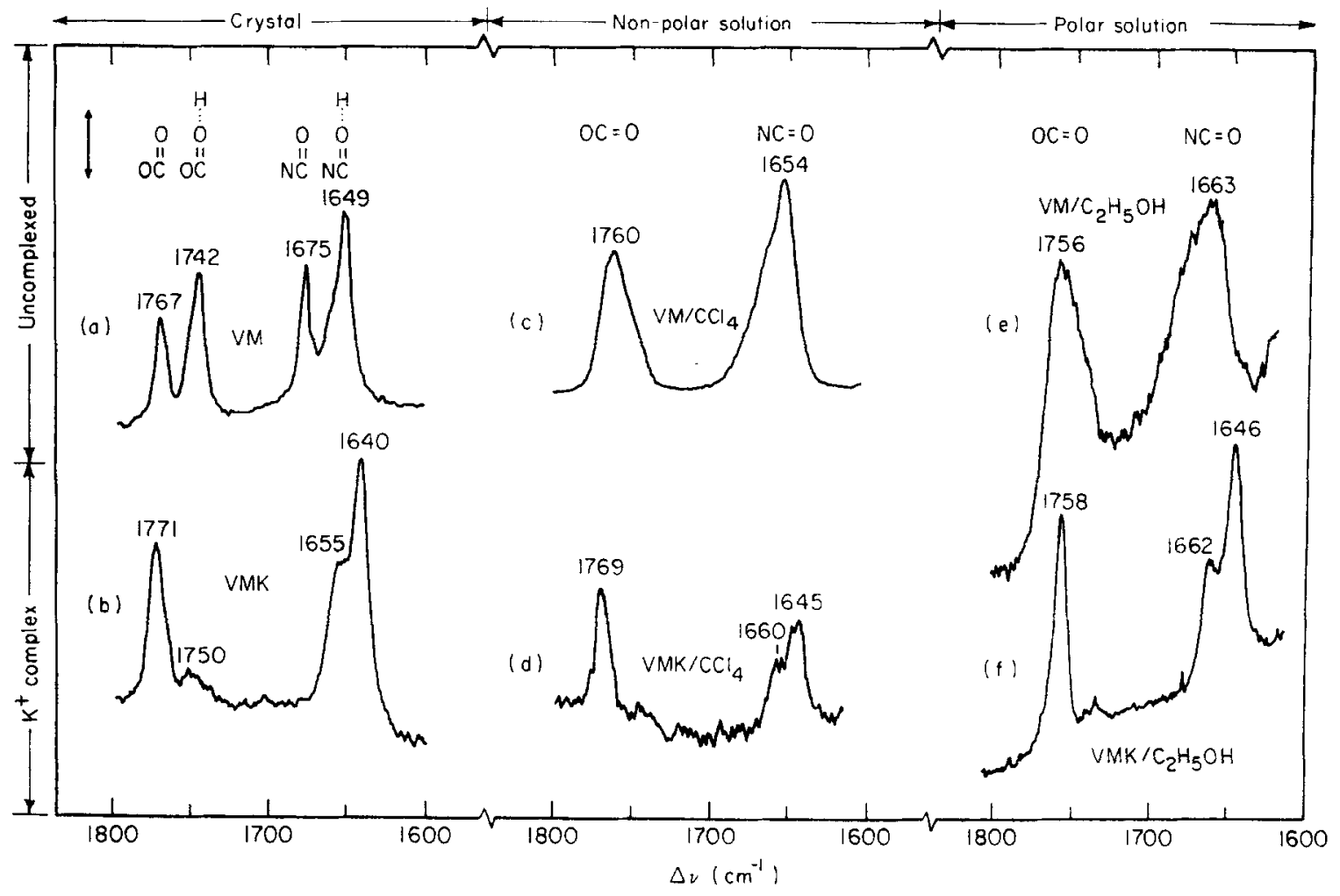

Fra. 2. Raman spectra of the $\mathrm{C}=\mathrm{O}$ stretch vibrations $\left(1600\right.$ to $\left.1800 \mathrm{~cm}^{-1}\right)$ of (a) orystalline uncomplexed valinomycin (VM); (b) crystalline valinomyoin-KSCN complex (VMK); (c) uncomplexed valinomycin in $\mathrm{CCl}_{4}$ solution; (d) valinomycin-KSCN complex in $\mathrm{CCl}_{4}$ solution; ( $(\theta)$ unoomplexed valinomycin in $\mathrm{C}_{2} \mathrm{H}_{5} \mathrm{OH}$ solution; (f) valinomycin-KSCN complex in $\mathrm{C}_{2} \mathrm{H}_{5} \mathrm{OH}$ solution. Spectral resolution: (a) and (c) $3 \mathrm{~cm}^{-1}$; (b) $4 \mathrm{~cm}^{-1}$; (d) to (f) $5 \mathrm{~cm}^{-1}$. Laser exoitation: (a), (b), (e) and (f) $4579 \AA$; (d) $4727 \AA$; (c) $4880 \AA$. Scanning speed : (b) $6 \mathrm{~cm}^{-1} / \mathrm{min}$; (c) $12 \mathrm{~cm}^{-1 /}$ min; (d), (e) and (f) $30 \mathrm{~cm}^{-1} / \mathrm{min}$; (a) $60 \mathrm{~cm}^{-1} / \mathrm{min}$. The vertical arrow corresponds to: (b) and (d) 100 ots/s; (a), (c), (e) and (f) 300 ots/s. Inoident power levels: (o), (o), (e) and (f) $100 \mathrm{~mW}$; (b) $90 \mathrm{~mW}$; (d) $60 \mathrm{~mW}$.

"free" and intramolecularly H-bonded ester $\mathrm{C}=\mathrm{O}$ groups $\left(1767 \mathrm{~cm}^{-1}\right.$ and 1742 $\mathrm{cm}^{-1}$, respectively). This interpretation is consistent with the $\mathrm{X}$-ray structure described by Duax et al. (1972) (Fig. 1(b)). We have recently shown (Rothschild et al., 1973; Asher et al., manuscript in preparation) that Raman spectra of uncomplexed valinomycin freshly recrystallized from o-dichlorobenzene or $p$-dioxane 
contain only the $1767 \mathrm{~cm}^{-1}$ ester $\mathrm{C}=0$ frequency, which implies a structure having no $\mathrm{H}$-bonded ester $\mathrm{C}=\mathrm{O}$ groups. This second conformation seems to resemble the predominant form of valinomycin in polar solvents as proposed by Ivanov et al. (1969) and Patel \& Tonelli (1973). This should make an X-ray determination of its structure more biologically relevant than that of valinomycin crystallized from $n$-octane.

\section{(a) Solid state}

The Raman spectrum (1600 to $1800 \mathrm{~cm}^{-1}$ ) of powdered valinomycin-KSCN complex (Fig. 2(b)) is strikingly different from that of uncomplexed valinomycin (Fig. 2(a)). The amide $\mathrm{C}=\mathrm{O}$ stretch vibrations appear as a cluse doublet at 1640 and $1655 \mathrm{~cm}^{-1}$. The latter peak is similar in frequency to the $1657 \mathrm{~cm}^{-1}$ shoulder observed in uncomplexed valinomycin powder, and the $1654 \mathrm{~cm}^{-1}$ band observed in $\mathrm{CCl}_{4}$ and $\mathrm{CHCl}_{3}$ solutions (Table 1), but the $1640 \mathrm{~cm}^{-1}$ frequency is $9 \mathrm{~cm}^{-1}$ lower than the lowest amide $\mathrm{C}=\mathrm{O}$ stretch vibration of uncomplexed valinomycin.



FIa. 3. Raman spectra (150 to $1200 \mathrm{~cm}^{-1}$ ) of (a) crystalline uncomplexed valinomycin-KSCN complex (VMK); and solutions of the valinomyoin-KSCN complex in (o) $\mathrm{CCl}_{4}$, (d) $\mathrm{CHCl}_{3}$ and (e) $\mathrm{C}_{2} \mathrm{H}_{5} \mathrm{OH}$. Spectral resolution: $5 \mathrm{~cm}^{-1}$ (except (a) $3 \mathrm{~cm}^{-1}$ ). Laser excitation: 4579 A (except (c) 4727 A). Scanning speed: (a) $60 \mathrm{~cm}^{-1} / \mathrm{min}$; (b), (d) and (e) $30 \mathrm{~cm}^{-1} / \mathrm{min}$; (c) $6 \mathrm{~cm}^{-1} / \mathrm{min}$. The vertical arrow corresponds to: $300 \mathrm{cts} / \mathrm{s}$ (except (c) $100 \mathrm{cts} / \mathrm{s}$; and (b) 150 to $380 \mathrm{~cm}^{-1}$ $1000 \mathrm{cts} / \mathrm{s}$ ). Incident power levels (a) $100 \mathrm{~mW}$; (b) to (d) $60 \mathrm{~mW}$; (e) $50 \mathrm{~mW}$. $\mathrm{S}$ denotes solvent peaks. VM, valinomycin. 


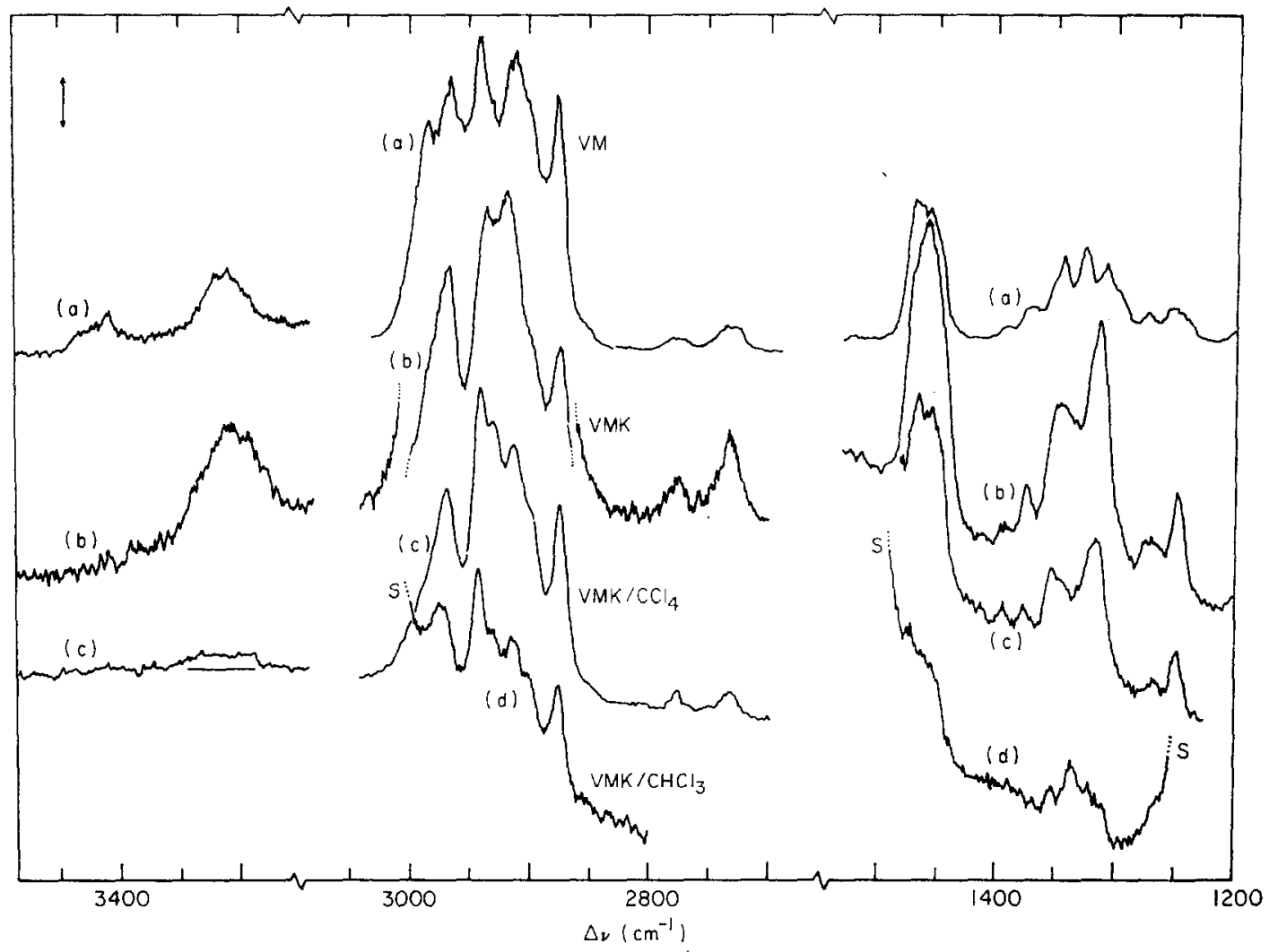

Fia. 4. Raman apeotra (1200 to $1400 \mathrm{~cm}^{-1}, 2700$ to $3100 \mathrm{~cm}^{-1}, 3250$ to $3480 \mathrm{~cm}^{-1}$ ) of (a) crystalline uncomplexed valinomycin (VM); (b) crystalline valinomycin-KSCN complex (VMK); and solutions of the valinomycin-KSCN complex in (c) $\mathrm{CCl}_{4}$, (d) $\mathrm{CHCl}_{3}$. Conditions as in Fig. 3, except in (b) where: the scanning speed is $6 \mathrm{~cm}^{-1} / \mathrm{min}\left(1200\right.$ to $1500 \mathrm{~cm}^{-1}$ and 2700 to $2960 \mathrm{~cm}^{-1}$ ), $12 \mathrm{~cm}^{-1} / \mathrm{min}\left(2860\right.$ to $\left.3000 \mathrm{~cm}^{-1}\right), 30 \mathrm{~cm}^{-1}\left(3250\right.$ to $\left.3480 \mathrm{~cm}^{-1}\right)$; the spectral resolution is 5 $\mathrm{cm}^{-1}$, except $2 \mathrm{~cm}^{-1}\left(2700\right.$ to $\left.2860 \mathrm{~cm}^{-1}\right)$; the incident power is $90 \mathrm{~mW}$, except $60 \mathrm{~mW}$ (3250 to $\left.3480 \mathrm{~cm}^{-1}\right)$, and the vertical line represents $300 \mathrm{cts} / \mathrm{min}$, except $100 \mathrm{cts} / \mathrm{s}\left(2700\right.$ to $2860 \mathrm{~cm}^{-1}$ ). S donotos solvent poaks.

The ester $\mathrm{C}=\mathrm{O}$ stretch vibration of powdered valinomycin-KSCN appears as a prominent single peak at $1771 \mathrm{~cm}^{-1}$, which is slightly above the free ester $\mathrm{C}=0$ frequency of uncomplexed valinomycin $\left(1767 \mathrm{~cm}^{-1}\right)$. There is a small peak near $1750 \mathrm{~cm}^{-1}$ which may represent a minority conformation (a similar small peak appears as a shoulder at $1747 \mathrm{~cm}^{-1}$ in uncomplexed valinomycin).

\section{(b) Non-polar solvents}

Both valinomycin and its $\mathrm{KSCN}$ complex dissolve readily in $\mathrm{CCl}_{4}$. The amide and ester $\mathrm{C}=\mathrm{O}$ vibrations of uncomplexed valinomycin in $\mathrm{CCl}_{4}$ solution appear as asymmetric broad $\left(\sim 25 \mathrm{~cm}^{-1}\right)$ bands in solution (Fig. 2(c)). This indicates that these $\mathrm{C}=\mathrm{O}$ groups now exist in a variety of different local environments with varying degrees of exposure to (and interactions with) the solvent (Rothschild et al., manuscript in preparation). In fact independent evidence exists to show that a mixture of several conformations is present (Shemyakin et al., 1969; Patel \& Tonelli, 1973). 


\section{TABLE 1}

$C-O$ stretch frequencies $\left(\mathrm{cm}^{-1}\right)$ of valinomycin and its $K^{+}$complex

(a) Uncomplexed valinomycin

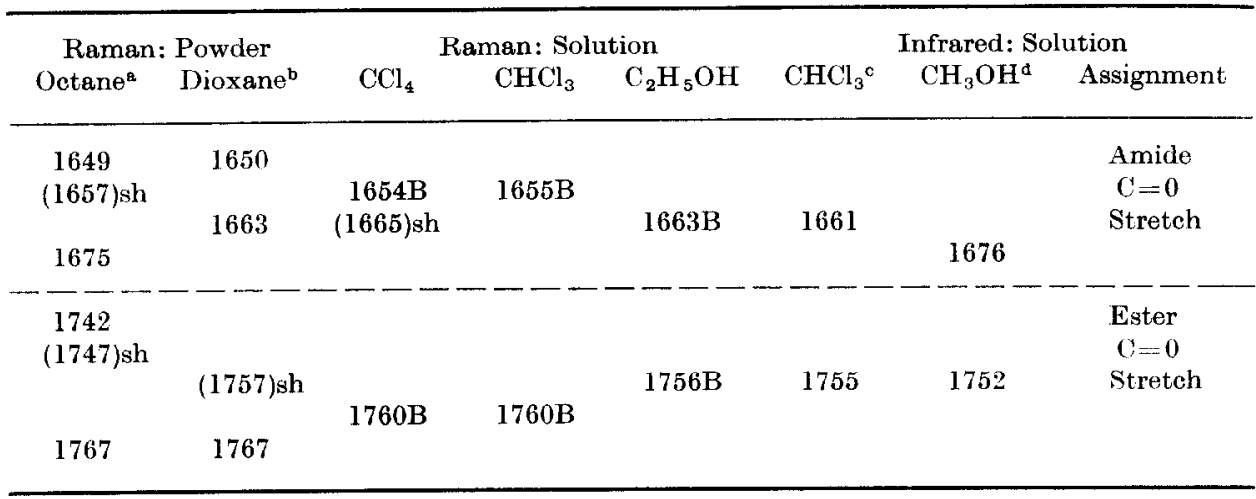

(b) Valinomycin-KSCN

\begin{tabular}{|c|c|c|c|c|c|c|c|}
\hline Methanol $^{\mathrm{e}}$ & Octane $^{f}$ & $\mathrm{CCl}_{4}$ & $\mathrm{CHCl}_{3}$ & $\mathrm{C}_{2} \mathrm{H}_{5} \mathrm{OH}$ & $\mathrm{CHCl}_{3}{ }^{\mathrm{C}}$ & $\mathrm{CH}_{3} \mathrm{OH}^{\mathrm{d}}$ & Assignment \\
\hline $\begin{array}{l}1640 \\
1655\end{array}$ & $\begin{array}{r}1644 \\
(\sim 1660)\end{array}$ & $\begin{array}{l}1645 \\
1660 \mathrm{sh}\end{array}$ & $\begin{array}{l}1646 \mathrm{~B} \\
1664\end{array}$ & $\begin{array}{l}1646 \\
1662 \mathrm{sh}\end{array}$ & 1657 & 1658 & $\begin{array}{l}\text { Amide } \\
\mathbf{C}=0 \\
\text { Stretch }\end{array}$ \\
\hline$(1750)$ & 1775 & (1741) & 1755 & 1758 & 1739 & 1745 & $\begin{array}{c}\text { Ester } \\
\mathrm{C}=0 \\
\text { Stretch }\end{array}$ \\
\hline
\end{tabular}

(c) Complex formation shifts $[(b)-(a)]$

\begin{tabular}{|c|c|c|c|c|c|c|c|}
\hline Powder & Octane $e^{r, h}$ & $\mathrm{CCl}_{4}$ & $\mathrm{CHCl}_{3}$ & $\mathrm{C}_{2} \mathrm{H}_{5} \mathrm{OH}$ & $\mathrm{CHCl}_{3}$ & $\mathrm{CH}_{3} \mathrm{OH}$ & Assignment \\
\hline $\begin{array}{r}-9 \\
-20\end{array}$ & $\begin{array}{r}-5 \\
-15\end{array}$ & $\begin{array}{c}-9 \\
-(5)\end{array}$ & -9 & -17 & -4 & -18 & $\begin{array}{c}\text { Amide } \\
C=0 \\
\text { Stretch }\end{array}$ \\
\hline+4 & +8 & +9 & -5 & +2 & -16 & -7 & $\begin{array}{l}\text { Ester } \\
\mathrm{C}=0 \\
\text { Streteh }\end{array}$ \\
\hline
\end{tabular}

- Valinomycin powder crystallized from warm $n$-octane (Calbiochem).

b Valinomycin powder recrystallized from $p$-dioxane.

c From Ivanov et al. (1969) and Shemyakin et al. (1969).

a From Grell \& Funck (1973).

- Grown from methanol (or ethanol) solution.

${ }^{2}$ Valinomycin-KSCN powder (e) at the bottom of a capillary tube filled with $n$-uetane (valinomycin is not readily dissolved in octane at room temperature).

r Powder (e) - powder (a).

${ }^{\mathrm{h}}$ Powder (f) - powder (a).

Abbreviations used: sh, shoulder; B, broad; () frequency uncertain. 


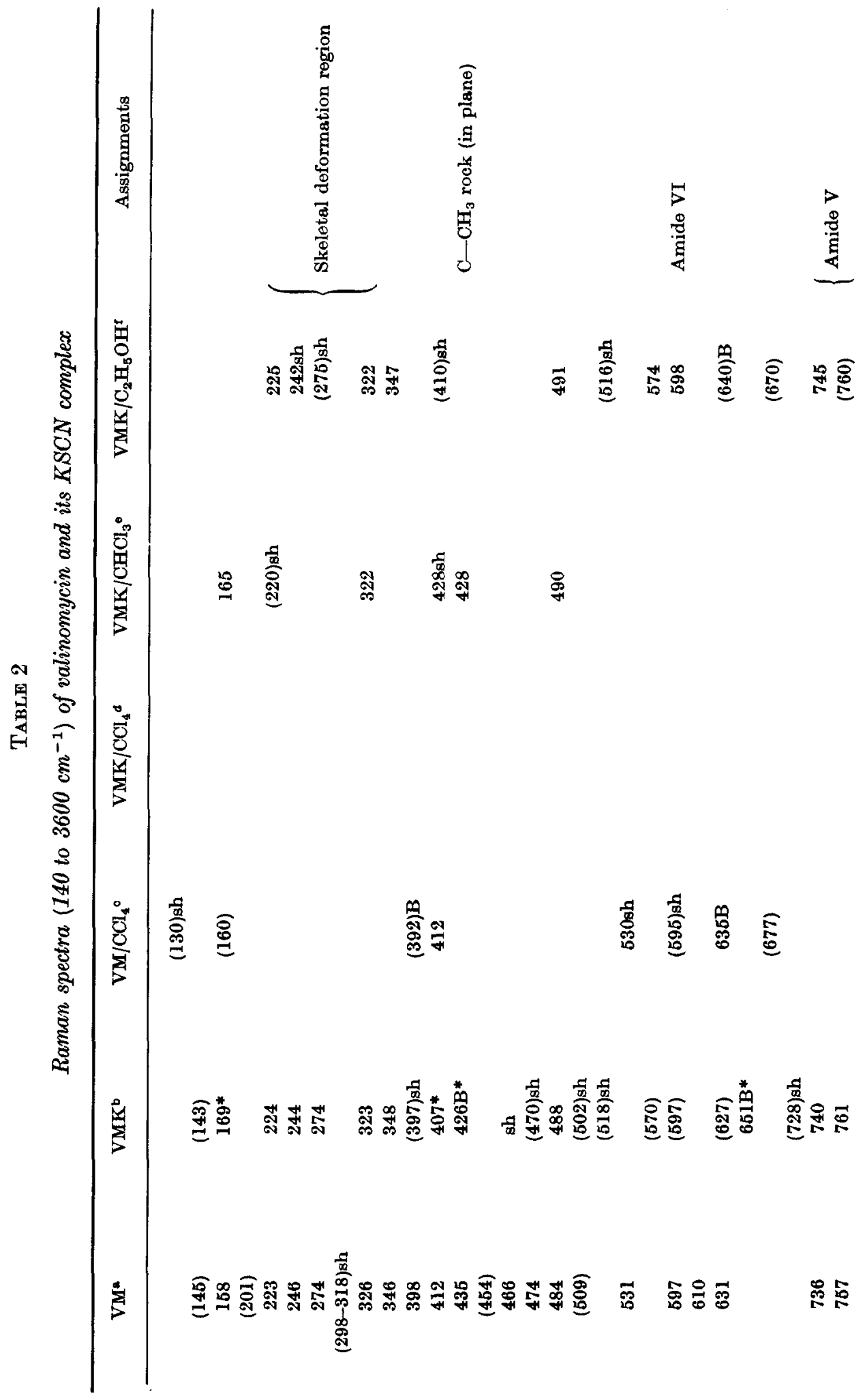




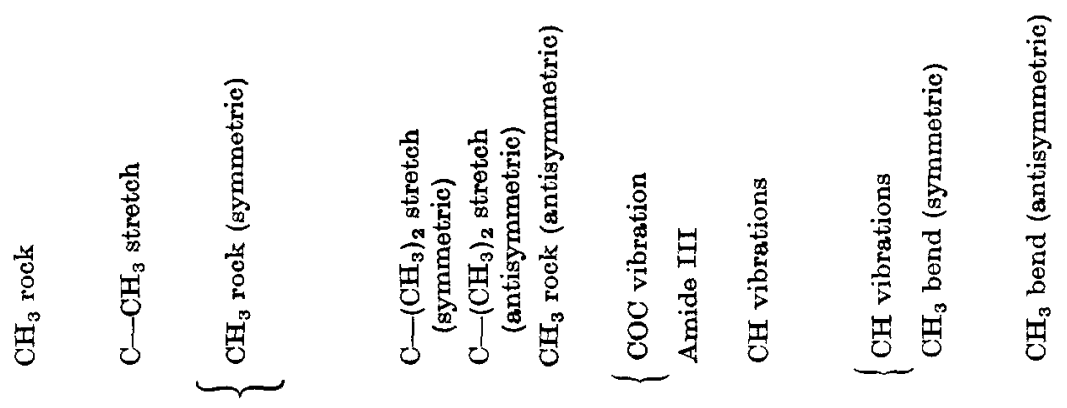

용

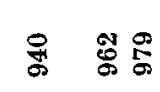

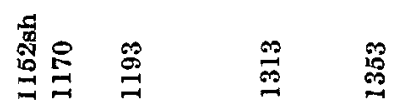

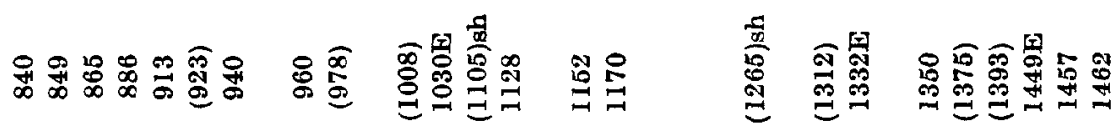

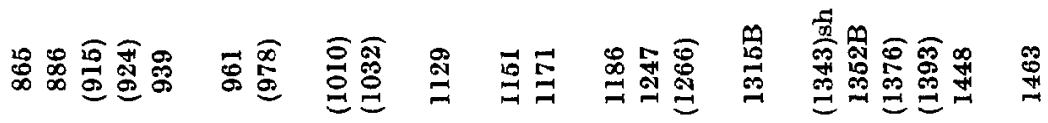

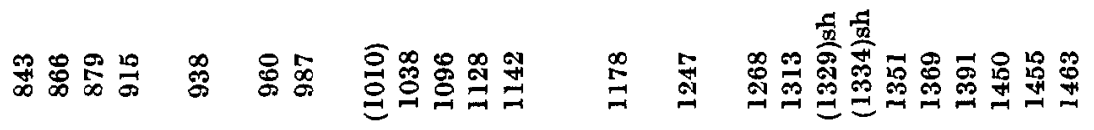

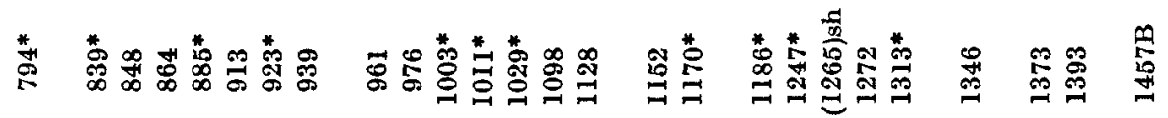

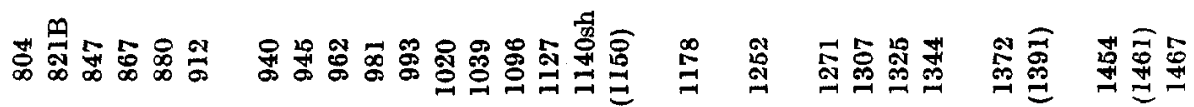




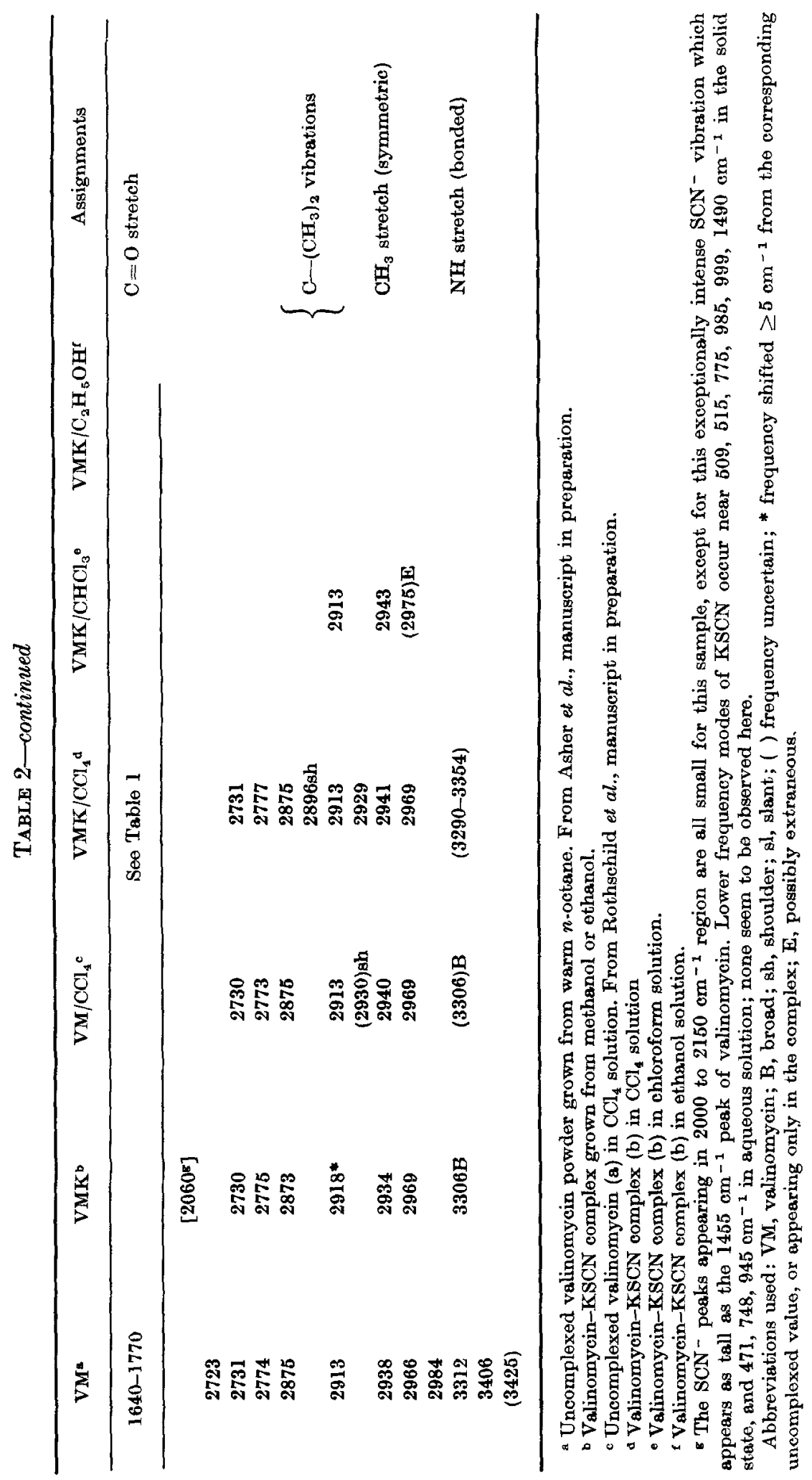


Raman spectra of $\mathrm{CCl}_{4}$ solutions of the valinomycin-KSCN complex (Fig. 2(d)) show a dramatic narrowing of the ester $\mathrm{C}=0$ peak which has about the same width $\left(\sim 10 \mathrm{~cm}^{-1}\right)$ and frequency $\left(1769 \mathrm{~cm}^{-1}\right)$ as in the solid state. This narrowing, an expected result of complex formation, is not observable in solid-state samples (Fig. 2 (b)) since the $C=0$ peaks of uncomplexed valinomycin powder are already quite narrow, i.e. the sample is already "locked" into a single, well-characterized conformation. The frequencies of the amide $\mathrm{C}=0$ bands $\left(1645 \mathrm{~cm}^{-1}, 1660 \mathrm{~cm}^{-1}\right)$ fall between those observed in the crystalline complex $\left(1640 \mathrm{~cm}^{-1}, 1655 \mathrm{~cm}^{-1}\right)$ and those observed in $\mathrm{CCl}_{4}$ solutions of uncomplexed valinomycin $\left(1654 \mathrm{~cm}^{-1}, 1665 \mathrm{~cm}^{-1}\right)$.

\section{(c) Polar solvents}

Complex formation-induced narrowing of the ester $\mathrm{C}=0$ band of valinomycin is also observed in the polar solvents $\mathrm{CHCl}_{3}$ and $\mathrm{C}_{2} \mathrm{H}_{5} \mathrm{OH}$ (Fig. 2(f)). In $\mathrm{CHCl}_{3}$ (Table 1) the ester $\mathrm{C}=\mathrm{O}$ stretch frequency of the complex $\left(1755 \mathrm{~cm}^{-1}\right)$ is $\sim 5 \mathrm{~cm}^{-1}$ below that of uncomplexed valinomycin in the same solvent $\left(1760 \mathrm{~cm}^{-1}\right)$. Although the Raman spectra of uncomplexed valinomycin in $\mathrm{CCl}_{4}$ and $\mathrm{CHCl}_{3}$ solutions appear almost identical in this region, the ester $\mathrm{C}=\mathbf{O}$ stretch frequency of the complex is $\sim 14 \mathrm{~cm}^{-1}$ lower in $\mathrm{CHOl}_{3}$.

The ester $\mathrm{C}=0$ frequencies of both complexed and uncomplexed valinomycin in ethanol are near $1757 \mathrm{~cm}^{-1}$, and both are below the corresponding peaks in $\mathrm{ClC}_{4}$ solutions of valinomycin resulted in spectra similar to those shown in Figure 2(f) solvent-independent.

Several additional procedures were carried out to verify the existence of the valinomycin- $\mathrm{K}^{+}$complex in $\mathrm{C}_{2} \mathrm{H}_{5} \mathrm{OH}$. Samples obtained by two different methods (see Materials and Methods) were found to yield identical Raman spectra. Optical rotatory dispersion measurements confirmed the presence of a single maximum near $220 \mathrm{~nm}$, characteristic of the complex conformation (Shemyakin et al., 1969), and the absence of the "polar" (200 nm) and "non-polar" ( $240 \mathrm{~nm})$ conformations observed in $\mathrm{C}_{2} \mathrm{H}_{5} \mathrm{OH}$ solutions of uncomplexed valinomycin. The addition of $\mathrm{KCl}$ to $\mathrm{C}_{2} \mathrm{H}_{5} \mathrm{OH}$ solutions of valinomycin resulted in spectra similar to those shown in Figure 2(f) (valinomycin $\mathrm{KSCN}$ complex), whereas the addition of $\mathrm{NaCl}$ produced no changes from those in Figure 2(e) (uncomplexed valinomycin in $\mathrm{C}_{2} \mathrm{H}_{5} \mathrm{OH}$ ).

\section{(d) Raman spectrum outside the 1600 to $1800 \mathrm{~cm}^{-1}$ region}

Comparisons of the complete Raman spectra (140 to $3600 \mathrm{~cm}^{-1}$ ) of valinomycin and its KSCN complex (Figs 3 and 4; Table 2) reveal several differences in addition to those occurring in the 1600 to $1800 \mathrm{~cm}^{-1}$ region. Several peaks $(488,864,939$, $1152 \mathrm{~cm}^{-1}$ ) are greatly increased in relative intensity on complex formation. Some peaks appear only in the complex $\left(651,794,923 \mathrm{~cm}^{-1}\right)$; others $\left(1325,2984 \mathrm{~cm}^{-1}\right)$ occur only in the uncomplexed form. The $1178 \mathrm{~cm}^{-1}$ single peak of uncomplexed valinomycin (COC stretch) splits into a $1170,1186 \mathrm{~cm}^{-1}$ doublet in the complex; and the $1252 \mathrm{~cm}^{-1}$ amide III vibrations shift to $1247 \mathrm{~cm}^{-1}$. Other complex formationinduced frequency shifts involve the $407,839,885$ and $1003 \mathrm{~cm}^{-1}$ vibrations.

It is significant that major changes occur in the 1300 to $1350 \mathrm{~cm}^{-1}$ and 2900 to $2950 \mathrm{~cm}^{-1}$ spectral regions upon complex formation. The peaks of these regions represent, primarily, bending and stretching modes involving the hydrocarbon side groups of valinomycin. There are further changes in the frequency and relative 
intensity of these modes on dissolving the valinomycin-KSCN complex in $\mathrm{CCl}_{4}$ or $\mathrm{CHCl}_{3}$. Frequencies in the 1000 to $1050 \mathrm{~cm}^{-1}$ region (valyl symmetric stretch) also shift on complex formation; although the $1127 \mathrm{~cm}^{-1}$ vibration (valyl antisymmetric stretch) does not.

In the solid state, the amide III vibration near $1250 \mathrm{~cm}^{-1}$ increases somewhat in relative intensity upon complexation. There may be additional amide III contributions to the $\mathrm{CH}$ band near $1313 \mathrm{~cm}^{-1}$.

\section{Discussion}

Since the biological significance of valinomycin hinges upon its ability to shield cations $\left(\mathrm{K}^{+}, \mathrm{Rb}^{+}, \mathrm{Cs}^{+}\right)$from the non-polar interior of lipid membranes, an investigation of the valinomycin- $\mathrm{K}^{+}$complex in non-polar solvents is particularly important. The Raman spectra of valinomycin-KSCN in the solid state and in $\mathrm{CCl}_{4}$ solution (Figs 2 to 4) are found to be similar except for changes in the amide $\mathrm{C}=0$ stretch (1600 to $1700 \mathrm{~cm}^{-1}$ ) and valyl stretch (2850 to $3000 \mathrm{~cm}^{-1}$ ) regions. The former may reflect the breaking of weak intermolecular hydrogen bonds (or the weakening of ionic bonds to the counterion) in solution. The latter may reflect the steric effects of the close packing of the complex (and its counterion) in the solid state. Thus the $\mathrm{X}$-ray structure of the crystalline complex (Pinkerton et al., 1969) would appear to be relevant to non-polar solutions as well. In contrast, Raman spectra of the complex in polar solvents display appreciable frequency shifts in the ester $\mathrm{C}=\mathrm{O}$ stretch region (1740 to $1780 \mathrm{~cm}^{-1}$ ) which apparently reflect solvent interactions in the vicinity of the cation co-ordinated by theso groups.

In the following sections we discuss our results in the amide (section (a)) and ester (section (b)) $\mathrm{C}=\mathrm{O}$ stretch regions and in the remainder of the Raman spectrum (section (c)). The significance of the observed solvent-dependence of the ester $\mathrm{C}=\mathrm{O}$ stretch frequency is elaborated upon in section (d). We also compare our results with those obtained by other methods.

\section{(a) The amide $C=O$ region (1600 to $1700 \mathrm{~cm}^{-1}$ )}

The amide $\mathrm{C}=\mathrm{O}$ stretch region of the valinomycin-KSCN complex displays close doublets (Fig. 2(b), (d) and (f)) with frequencies below those of uncomplexed valinomycin $\left(1649,1675 \mathrm{~cm}^{-1}\right)$. The absence of the $1675 \mathrm{~cm}^{-1}$ peak indicates that now all amide $\mathrm{C}=\mathrm{O}$ groups are $\mathrm{H}$-bonded. The down-shift in the lower peak may represent an increase in the strength of the intramolecular $\mathrm{H}$-bonding of some amide $\mathrm{C}=\mathrm{O}$ groups beyond that of the "strong" H-bonds of uncomplexed valinomycin. The smallangle X-ray diffraction measurements of Krigbaum et al. (1972) show that the radius of gyration of valinomycin molecules in $\mathrm{C}_{2} \mathrm{H}_{5} \mathrm{OH}$ solutions drops from $\sim 5.0 \AA$ to $\sim 3.9 \AA$ on adding KSCN. However, $\mathrm{X}$-ray diffraction measurements of the N. . O distances of complexed and uncomplexed valinomycin crystals vary only between $\sim 2.8$ and $3.0 \AA$ in both cases (Pinkerton et al., 1969; Duax personal communication). Our attribution of the complex formation-induced downshift in the former amide $\mathrm{C}=\mathrm{O}$ stretch frequencies to increased hydrogen bonding is supported by proton nuclear magnetic resonance studies of the NH groups of valinomycin. The valine temperature coefficient shifts from $\sim 75 \times 10^{-4}$ p.p.m./deg. $\mathrm{C}$ in dioxane/water solution (in which valinomycin lacks strong hydrogen bonds) to $\sim 30 \times 10^{-4}$ p.p.m.l deg. $\mathrm{C}$ in dioxane/octane solution (in which all NH groups are strongly hydrogen 
bonded; Patel \& Tonelli 1973). Significantly, these coefficients are still lower $\sim 19 \times$ $10^{-4}$ p.p.m./deg. $\mathrm{C}$ in the valinomycin-KSCN complex in $\mathrm{CH}_{3} \mathrm{OH}$ (Ohnishi \& Urry 1970).

The appearance of a close, but well resolved, amide $\mathrm{C}=\mathbf{O}$ doublet in the Raman spectrum of the complex (Fig. 2), suggests that hydrogen bonds to these groups may be of two discrete, slightly different strengths. This conclusion is supported by recent ${ }^{13} \mathrm{C}$ nuclear magnetic resonance spectra of valinomycin in $\mathrm{CD}_{3} \mathrm{OD}$ (Patel, 1973), which show two amide $\mathrm{C}=0$ resonances with chemical shifts of 20.64 and 21.76 p.p.m. On complex formation with KSCN these shift, respectively, 1.3 and 0.9 p.p.m. further downfield. (The other two resonances of this region shift 3.6 and 5.1 p.p.m. downfield on complex formation, and were therefore assigned to ester $\mathrm{C}=0$ groups.) The observed shifts led Bystrov et al. (1972) to suggest that the amide $\mathrm{C}=\mathrm{O}$ groups may also be interacting directly (albeit weakly) with the $\mathrm{K}^{+}$ion.

We find the amide $\mathrm{C}=\mathrm{O}$ frequencies of the valinomycin-KSCN complex to be virtually independent of solvent polarity (Fig. 2(d) and (f); Table 1). This may be attributed to the strong hydrogen-bonding of these groups, and their shielding by the hydrocarbon side-groups of valinomycin. The appearance of this region in Raman spectra of uncomplexed valinomycin (Fig. 2(c) and (e)) is solvent-dependent due to shifts in the equilibrium concentrations of several, simultaneously-present conformers (Ivanor et al., 1969; Patel \& Tonelli, 1973). The amide $\mathrm{C}=\mathrm{O}$ frequencies of the valinomycin-KSCN complex are $\sim 5 \mathrm{~cm}^{-1}$ lower in the solid state (Fig. 2 (b)) than in solution. This may reflect additional bonding of these groups to adjacent valinomycin molecules or $\mathrm{SCN}^{-}$anions in the crystal lattice.

\section{(b) The ester $C=O$ region (1700 to $1800 \mathrm{~cm}^{-1}$ )}

Raman spectra of the valinomycin-KSCN complex in both the solid state and in non-polar $\left(\mathrm{CCl}_{4}\right)$ solution display a single, narrow, intense ester $\mathrm{C}=0$ peak near $1770 \mathrm{~cm}^{-1}$. This suggests: (i) that all six ester $\mathrm{C}=0$ groups are similarly bonded; (ii) that these groups are "locked" into position and shielded from the non-polar solvent (which explains the dramatic narrowing of this peak, compared to that of uncomplexed valinomycin, in $\mathrm{CCl}_{4}$ ); (iii) that the structure of this (presumably inner) portion of the complex is the same in both the solid state and in non-polar solution. These observations are consistent with the $\mathrm{X}$-ray crystallographic structure of the valinomycin- $\mathrm{KAuCl}_{4}$ enmplex (Fig. $\mathrm{I}(\mathrm{c})$ ) determined by Pinkerton et al. (1969) in which all six ester $\mathrm{C}=0$ groups co-ordinate the enclosed cation. No parallel studies (nuclear magnetic resonance, infrared absorption) of valinomycin complexes in the solid state, or in simple (non-hydrogen-bonding) non-polar solutions, are available.

It is not surprising that this frequency $\left(1771 \mathrm{~cm}^{-1}\right.$ in solid state, $1769 \mathrm{~cm}^{-1}$ in $\left.\mathrm{CCl}_{4}\right)$ is higher than both the "free" $\left(1767 \mathrm{~cm}^{-1}\right)$ and hydrogen-bonded $\left(1742 \mathrm{~cm}^{-1}\right)$ ester $\mathrm{C}=0$ stretch frequencies of crystalline uncomplexed valinomycin (or the $1760 \mathrm{~cm}^{-1}$ frequency in $\mathrm{CCl}_{4}$ solution). The co-ordination of the $\mathrm{K}^{+}$ion modifies the electron density distribution in the vicinity of the $\mathrm{C}=\mathrm{O}$ bond, shifting it further toward the oxygen atom; this changes the effective carbon-oxygen force constant (the second spatial derivative of the local potential energy along the bond). Thus the relative effects of hydrogen-bonding and $\mathrm{K}^{+}$co-ordination on the $\mathrm{C}=\mathrm{O}$ stretch frequency cannot be predicted a priori, except by combining a normal mode analysis (opposing $\mathrm{C}=\mathrm{O}$ groups are coupled via the cation) with a local solution of the Schrödinger 
equation. Such effects are usually investigated empirically, e.g. by comparing a series of model compounds. For example, it was found that hydrogen bonding consistently lowered the frequency of the amide $\mathrm{C}=0$ stretch vibration (Richards \& Thompson, 1947; Koenig, 1972). This is an additional reason for attributing the narrowing of ester $\mathrm{C}=\mathrm{O}$ peaks unaccompanied by a frequency shift (Fig. 2(e) and (f)) to some process other than hydrogen bonding.

Narrowing of the ester $\mathrm{C}=0$ stretch band in the moderately polar solvents, $\mathrm{CHCl}_{3}$ and $\mathrm{C}_{2} \mathrm{H}_{5} \mathrm{OH}$ (Fig. 2(f)), verifies the existence of valinomycin-KSCN complex formation in these solvents as well; however, the ester $\mathrm{C}=\mathrm{O}$ frequency of the complex $\left(1755 \mathrm{~cm}^{-1}\right.$ in $\mathrm{CHCl}_{3}, 1758 \mathrm{~cm}^{-1}$ in $\left.\mathrm{C}_{2} \mathrm{H}_{5} \mathrm{OH}\right)$ is $\sim 12 \mathrm{~cm}^{-1}$ lower than its value in $\mathrm{CCl}_{4}$ solution (Fig. 2(d)). In contrast, the corresponding spectra of uncomplexed valinomycin in $\mathrm{CCl}_{4}$ and $\mathrm{CHCl}_{3}$ solutions are similar (Table 1); both display broad bands with peaks near $1760 \mathrm{~cm}^{-1}$. This sensitivity of the ester $\mathrm{C}=0$ frequency to the solvent is striking since:

(i) the X-ray crystallographic structure of the complex (Fig. 1(c)) has all six ester $\mathrm{C}=\mathrm{O}$ groups substantially shielded by surrounding parts of the molecule (Pinkerton et al., 1969);

(ii) in any case, the ester $\mathrm{C}=0$ groups should be less available in the complex (in which they co-ordinate the $\mathrm{K}^{+}$ion) than in the rather open structures of uncomplexed valinomycin solution (in which the ester C-O groups are "free"; Shemyakin et al. (1969); Patel \& Tonelli (1973));

(iii) the amide $\mathrm{C}=\mathrm{O}$ frequencies of the complex are virtually identical in $\mathrm{CCl}_{4}$, $\mathrm{CHCl}_{3}$ and $\mathrm{C}_{2} \mathrm{H}_{5} \mathrm{OH}$ (Fig. 2(d) and (f); Table 1).

It is interesting to compare these Raman results with infrared absorption measurements of the valinomycin- $\mathrm{KC}_{11} \mathrm{H}_{23} \mathrm{OSO}_{3}$ complex in $\mathrm{CHCl}_{3}$ (Shemyakin et al., 1969) and the valinomycin- $\mathrm{KCl}$ complex in $\mathrm{CH}_{3} \mathrm{OH}$ (Grell \& Funck, 1973). The infrared and Raman $\mathrm{C}=\mathrm{O}$ frequencies differ numerically in all cases (Table 1); this is not surprising since Raman-active vibrations are often infrared-inactive (or vice versa) depending on the symmetry and selection rules which characterize the vibration. Complex formation in $\mathrm{CHCl}_{3}$ shifts the infrared stretch frequencies of both the amide and ester $\mathrm{C}=0$ groups downward $\left(4 \mathrm{~cm}^{-1}, 16 \mathrm{~cm}^{-1}\right.$, respectively); the corresponding Raman displacements are also downward but different in magnitude $\left(9 \mathrm{~cm}^{-1}\right.$, $5 \mathrm{~cm}^{-1}$, respectively). Complex formation in $\mathrm{CH}_{3} \mathrm{OH}$ (or $\mathrm{C}_{2} \mathrm{H}_{5} \mathrm{OH}$ ) shifts both the infrared and Raman amide $\mathrm{C}=0$ frequencies markedly downward $\left(\sim 17 \mathrm{~cm}^{-1}\right)$; but the corresponding ester $\mathrm{C}=0$ frequencies are shifted $7 \mathrm{~cm}^{-1}$ downward in the infrared, and $2 \mathrm{~cm}^{-1}$ upward in the Raman.

Despite differences in the Raman and infrared frequencies (arising from differences in modes observed and perhaps the choice of counterions as well), these infrared measurements support our conclusions that:

(i) the amide $\mathrm{C}=\mathrm{O}$ frequencies of the complex are about the same in $\mathrm{CHCl}_{3}$ and $\mathrm{C}_{2} \mathrm{H}_{5} \mathrm{OH}$ (or $\mathrm{CH}_{3} \mathrm{OH}$ );

(ii) the ester $\mathrm{C}=0$ frequency of the complex is significantly lower in $\mathrm{CHCl}_{3}$ than in $\mathrm{C}_{2} \mathrm{H}_{5} \mathrm{OH}$ (or $\mathrm{CH}_{3} \mathrm{OH}$ );

(iii) the downward shift of the amide $\mathrm{C}=0$ frequency on complex formation is largest in $\mathrm{C}_{2} \mathrm{H}_{5} \mathrm{OH}\left(\mathrm{CH}_{3} \mathrm{OH}\right)$, while that of the ester $\mathrm{C}=\mathrm{O}$ frequency is largest in $\mathrm{CHCl}_{3}$. 
Parallel infrared studies of valinomycin complexes in non-polar solvents like $\mathrm{CCl}_{4}$ might be helpful in verifying some of our other conclusions.

Although valinomycin and its KSCN complex are not readily soluble in octane at room temperature, Raman spectra of valinomycin-KSCN powder at the bottom of a capillary tube filled with $n$-octane yield a still higher ester $\mathrm{C}=0$ stretch frequency (1775 $\mathrm{cm}^{-1}$ ) that is $\sim 6 \mathrm{~cm}^{-1}$ above its value in $\mathrm{CCl}_{4}$, and $\sim 20 \mathrm{~cm}^{-1}$ above its value in $\mathrm{CHCl}_{3}$ (Table 1). Again the amide $\mathrm{C}=\mathrm{O}$ stretch frequencies are basically unchanged.

\section{(c) Raman spectrum outside the 1600 to $1800 \mathrm{~cm}^{-1}$ region}

Observations in other regions of the Raman spectrum of valinomycin (Table 2, Figs 3 and 4) support the existence of widespread conformational changes in the valinomycin backbone on complex formation (Fig. 1(b) and (c)). In particular, the splitting of the $1178 \mathrm{~cm}^{-1}$ peak into a sharp doublet $\left(1170,1186 \mathrm{~cm}^{-1}\right)$ reflects changes in the COC stretch mode induced by the reorientation of the neighboring ester $\mathbf{C}=\mathbf{O}$ groups in the complex. The latter groups also adjoin the valyl residues of the $L$ and $D$-valine subunits, which may account for the major changes which occur in the 1300 to $1350 \mathrm{~cm}^{-1}$ and 2900 to $2950 \mathrm{~cm}^{-1}$ regions on complex formation.

These observations are supported by studies using other techniques. Ivanov et al. (1971) report shifts in the $1184 \mathrm{~cm}^{-1}$ COC infrared absorption frequency of uncomplexed valinomycin in $\mathrm{CCl}_{4} / \mathrm{CH}_{3} \mathrm{CN}(2: 1 \mathrm{v} / \mathrm{v})$ solution from 1194 to $1197 \mathrm{~cm}^{-1}$ on the addition of $\mathrm{K}^{+}, \mathrm{Rb}^{+}, \mathrm{Cs}^{+}$or even $\mathrm{Na}^{+}$. Widespread changes in the valinomycin backbone on KSCN complex formation are observed in proton nuclear magnetic resonance spectra in $\mathrm{CDCl}_{3}$ (Haynes et al., 1969) and $\mathrm{CD}_{3} \mathrm{OD}$ and $\mathrm{CH}_{3} \mathrm{CN}$ (Ivanov et al., 1969). ${ }^{13} \mathrm{C}$ nuclear magnetic resonance studies of valinomycin-KSCN complex formation in $\mathrm{CDCl}_{3} / \mathrm{CD}_{3} \mathrm{OD}(1: 1 \mathrm{v} / \mathrm{v})$ (Bystrov et al., 1972) and $\mathrm{CH}_{3} \mathrm{OH}$ (Patel, 1973) indicate $\sim 3$ p.p.m. shifts for the $\mathrm{C}_{(a)}$ carbons of the valine subunits, but $\sim 1$ p.p.m. shifts for the $\mathrm{C}_{(a)}$ carbons of lactic and hydroxyisovaleric acid (which are further from the $\mathrm{K}^{+}$-binding ester $\mathrm{C}=0$ groups). Similarly $\sim 1 \cdot 3$ p.p.m. shifts are observed for the $\mathrm{C}_{(\beta)}$ carbons of valine but not for hydroxyisovaleric acid.

Finally, Ivanov et al. (1973) find far infrared evidence for a direct $\mathrm{K}^{+} \ldots \mathrm{O}$ stretching mode at $171 \mathrm{~cm}^{-1}$ in the valinomycin-K $\mathrm{K}^{+}$complex. Although we observe a mode of similar frequency $\left(169 \mathrm{~cm}^{-1}\right)$ in Raman spectra of the complex (Fig. 3), this may represent a frequency shift in the $158 \mathrm{~cm}^{-1}$ mode of uncomplexed valinomycin rather than the appearance of a new stretching mode.

\section{(d) Further discussion of results in the ester $C=O$ region}

The sensitivity of the ester $\mathrm{C}=\mathrm{O}$ stretch frequency of the valinomycin- $\mathrm{K}^{+}$complex to the polarity of the solvent is of great biological interest. It indicates that the enclosed ion and its surrounding ester $\mathrm{C}=\mathrm{O}$ groups still interact with nearby solvent molecules, suggesting that this interaction may be involved in the release mechanism for $\mathrm{K}^{+}$ions carried to the water interface on the far side of a lipid bilayer; it indicates further that the X-ray structure described by Pinkerton et al. (1969) may not reflect in detail the inner structure of the complex in polar solution. 
The valinomycin $\leftrightarrow$ valinomycin-KSCN exchange rate, as measured in proton nuclear magnetic resonance experiments, is also solvent dependent, e.g. it is $<0.2 \mathrm{~s}^{-1}$ in pure $\mathrm{CDCl}_{3}$, but $\sim 2.0 \mathrm{~s}^{-1}$ in $\mathrm{CH}_{3} \mathrm{OH} / \mathrm{CDCl}_{3}$ (4:1) (Haynes et al., 1969); a $\mathrm{K}^{+}$ turnover rate of $\sim 200 \mathrm{~s}^{-1}$ has been reported in mitochondrial preparations (Pressman et al., 1967).

The role of the counterion in complex formation must also be considered. Pinkerton et al. (1969) found complex formation with $\mathrm{K}^{+}$to be anion-dependent, with picrate ${ }^{-}$ and $\mathrm{AuCl}_{4}^{-}$giving the best results; their X-ray crystallographic measurements show that the $\mathrm{AuCl}_{4}^{-}$anion rests in a nearly spherical cavity formed by adjacent valinomycin-K $\mathbf{K}^{+}$complex molecules. They conclude that valinomycin selectively transports $\mathrm{K}^{+}$/picrate ${ }^{-}$pairs across a $\mathrm{CHCl}_{3}$ barrier from the fact that adding $\mathrm{KCl}$ to one side of the barrier effectively increases the migration of both $\mathrm{K}^{+}$and picrate ${ }^{-}$(but not $\mathrm{Cl}^{-}$) ions. The ability of valinomycin to solubilize $\mathrm{K}^{+}$in decane is also anion-dependent (Tosteson, 1972). Picrate analogs are superior to even such lipid-soluble anions as hexanoate; the trinitrocresolate anion was found to be the most potent (although it dramatically reduces the selectivity of valinomycin as well). The $\mathrm{SCN}^{-}$anion has been found to be closely associated with the co-ordinated $\mathrm{Rb}^{+}$ion in $\mathrm{X}$-ray crystallographic studies of the RbSCN-dibenzo-18-crown-6 polyether complex (Bright \& Truter, 1970). The SCN - ion is inserted from above the ring in this ion-pair complex. A similar role is played by the highly polar solvent $\mathrm{CH}_{3} \mathrm{CN}$ in the $\mathrm{Li}^{+}$antamanide complex (Karle et al., 1973; Karle, 1974a,b).

These results suggest that the negatively charged $\mathrm{AuCl}_{4}^{-}$ion may remain associated with the positively charged valinomycin- $\mathrm{K}^{+}$complex even in $\mathrm{CHCl}_{3}$ solution. If the same is true-perhaps in a lesser degree-of the valinomycin-KSCN complex: (i) the observed shift of the ester $\mathrm{C}=\mathrm{O}$ peak in polar solvents may reflect the increased dissociation of the anion in polar solvents; (ii) the ester $\mathrm{C}=\mathrm{O}$ groups might be particularly affected since they co-ordinate the positively charged cation, which could interact strongly with a nearby negative ion; (iii) the amide $\mathrm{C}=\mathbf{0}$ groups (which circle the ring equatorially) would be relatively unaffected by changes in the anion proximity, especially since the density of peripheral hydrocarbon groups is particularly high in that region. It should be noted, however, that recent ${ }^{13} \mathrm{C}$-nuclear magnetic resonance studies suggest that valinomycin forms no stable association with $\mathrm{ClO}_{4}^{-}$counterions in $\mathrm{CD}_{3} \mathrm{OD}$ solution (Fedarko, 1973).

Finally, none of our data directly contradicts the (unlikely) possibility that a totally different form of complex exists in $\mathrm{CHCl}_{3}$ and $\mathrm{C}_{2} \mathrm{H}_{5} \mathrm{OH}$ solution in which the amide $\mathrm{C}=0$ groups are solvent-protected and the ester $\mathrm{C}=0$ groups are solventexposed. Similarly, the assignment of the most KSCN-sensitive ${ }^{13} \mathrm{C}$ nuclear magnetic resonance carbonyl resonances of valinomycin in $\mathrm{CD}_{3} \mathrm{OD}$ to ester $\mathrm{C}=0$ groups was based on the a priori assumption that those groups co-ordinate the cation (Patel, 1973).

The situation in other hydrogen-bonding solvents is even more complex. Patel \& Tonelli (1973) observe a new, weakly H-bonded, complex conformation in dimethylformamide; recently an unusual mixture of valinomycin conformations has been observed in Raman spectra of dioxane solutions in contact with a KCl-saturated deuterium oxide phase (Rothschild et al., manuscript in preparation). These results indicate that a true understanding of the complex formation and transport mechanisms of valinomycin still requires considerable further research using all available techniques. In particular, polarization studies and investigations of anion effects are under way. 


\section{Conclusion}

We have obtained the first complete Raman spectra of the valinomycin- $\mathrm{K}^{+}$ complex in the solid state, and in non-polar $\left(\mathrm{CCl}_{4}\right)$ and polar $\left(\mathrm{CHCl}_{3}, \mathrm{C}_{2} \mathrm{H}_{5} \mathrm{OH}\right)$ solvents. Major spectral changes, such as the narrowing and frequency shifting of the amide and ester $\mathrm{C}=\mathrm{O}$ stretch peaks, differentiate complexed from unoomplexed valinomycin. The ester $\mathrm{C}=0$ stretch frequency is extremely solvent-sensitive; it is highest in non-polar solvents. In contrast the amide $\mathrm{C}=0$ stretch frequencies, while lower than in uncomplexed valinomycin, are solvent-independent.

These results suggest that the complex consists of a tight, rigid carbon framework within which the ester $\mathrm{C}=0$ groups and $\mathrm{K}^{+}$ion are only partially shielded from external solvent. Gaps in the outer covering of hydrocarbon side-chains could allow a closer approach of counterions or polar solvent molecules to the center of the complex than previously suspected. This hypothesis might be investigated further using valinomycin analogs in which the hydroxyisovaleric acid subunits are replaced with lactic acid or vice versa (such analogs have already been synthesized (Shemyakin et al., 1969)). Solvent interactions with the complexed cation may be a biologically significant part of the ion-release mechanism of such ion-carrying molecules.

We thank Professor V. T. Ivanov and his colleagues at the Shemyakin Institute of the Chemistry of Natural Products, Moscow, for providing a sample of their valinomycinKSCN complex; their help and generosity are deeply appreciated. We gratefully acknowledge the help and encouragement of Professor E. Anastassakis of Northeastern University, and stimulating conversations with Professor R. C. Lord, W. L. Duax, G. Phillies, A. Hewitt, Professor E. B. Carew, and B. Tokar. This work was supported by grants from the Research Corporation and grant HL14322-02 of the National Heart and Lung Institute (R. W. Mann, Principal Investigator). Partial equipment support was provided by the Research Corporation and a National Institutes of Health Biomedical Sciences Support grant, NIH-5-SO5-RR07047-08.

\section{REFERENCES}

Bright, D. \& Truter, M. R. (1970). Nature (London), 225, 176-177.

Bystrov, V. F., Ivanov, V. T., Koz'min, S. A., Mikhaleva, I. I., Khalilnlina, K. K., Ovchinnikov, Yu. A., Fedin, E. I. \& Petrovskii, P. V. (1972). FE BS Letters, 21, 34-38.

Duax, W. L., Hauptman, H., Weeks, C. M. \& Norton, D. A. (1972). Science, 176, 911-914. Fedarko, M. C. (1973). J. Magnetic Resonance, 12, 30-35.

Grell, E. \& Funck, T. (1973). J. Supramol. Struct. 1, 307-335.

Haynes, D. H., Kowalsky, A. \& Pressman, B. C. (1969). J. Biol. Chem. 244, 502-505.

Ivanov, V. T., Laine, I. A., Abdulaev, N. D., Senyavina, L. B., Popov, E. M., Ovchinnikov, Yu. A. \& Shemyakin, M. M. (1969). Biochem. Biophys, Res. Commun. 34, 803-811.

Ivanov, V. T., Laine, I. A., Abdullaev, N. D., Pletnev, V. Z., Linkind, G. M., Arkhinova, C. F., Senyavina, L. B., Mescheryakova, E. N., Ponov, E. M., Bistrov, V. F. \& Ovchinnikov, Yu. A. (1971). Khimia Prirodnikh Soedinenii, 3, 221-246.

Ivanov, V. 'T', Kogan, G. A., 'Tulchinsky, V. M., Miroshnikov, A. V., Mikhalyova, I. I., Evstratov, A. V., Zenkin, A. A., Kostetsky, P. V., Ovchinnikov, Yu. A. \& Lokshin, B. V. (1973). FEBS Letters, 30, 199-204.

Karle, I. L. (1974a). Biochemistry, 13, 2155-2162.

Karle, I. L. (1974b). J. Am. Chem. Soc. in the press.

Karle, I. L., Karle, J., Wieland, T., Burgermeister, W., Faulstich, H. \& Witkop, B. (1973). Proo. Nat. Acad. Sci., U.S.A. 70, 1836-1840.

Koenig, J. L. (1972). J. Polymer Sci. D60, 59-177.

Krigbaum, W. R., Kuegler, F. R. \& Oelschlaeger, H. (1972). Biochemistry, 11, 4548-4551.

Ohnishi, M. \& Urry, D. W. (1970). Science, 168, 1091-1092.

Patel, D. J. \& Tonelli, A. E. (1973). Biochemistry, 12, 486-496. 
Patel, D. J. (1973). Biochemistry, 12, 496-501.

Pinkerton, M., Steinrauf, L. K. \& Dawkins, P. (1969). Biochem. Biophys. Res. Commun. 35, 512-515.

Pressman, B. C. (1965). Proc. Nat. Acad. Sci., U.S.A. 53, 1076-1083.

Pressman, B. C., Harris, E. J., Jagger, W. S. \& Johnson, J. H. (1967). Proc. Nat. Acad. Sci., U.S.A. 58, 1949-1956.

Richards, R. \& Thompson, H. (1947). J. Chem. Soc. 1248-1260.

Rothschild, K. J., Asher, I. M., Anastassakis, E. \& Stanley, H. E. (1973). Science, 182, $384-386$.

Rothschild, K. J. \& Stanley, H. E. (1974). Science, 185, 616-618.

Shemyakin, M. M., Aldanova, N. A., Vinogradova, E. I. \& Feigina, M. Y. (1963). Tetrahedron Lett. 1921-1925.

Shemyakin, M. M., Ovchinnikov, Yu. A., Ivanov, V. T., Antonov, V. K., Vinogradova, E. I., Shkrob, A. M., Malenkov, G. G., Evstratov, A. V., Laine, I. A., Melnik, E. I. \& Ryabova, I. D. (1969). J. Membrane Biology, 1, 402-430.

Tusteson, D. C. (1972). In Perspectives in Membrane Biophysics (Agin, D. P., ed.), pp. 129145, Gordon and Breach Scientific Publications, New York.

Note added in proof: Recently, the technique of laser Raman spectroscopy has been used to provide information germane to the conformations of gramicidin $\mathbf{A}$ (Rothschild \& Stanley, 1974), nonactin (Asher, Phillies \& Stanley, manuscript in preparation), and other membrane-active antibiotics. 